\title{
Strategic Insight on Gaining Admittance to Graduate Study
}

\author{
Sheryl M. Strasser ${ }^{1}$, Lucy Annang ${ }^{2}$, Jessica L. Muilenburg ${ }^{3}$, Marc O. Etienne ${ }^{4}$ \\ ${ }^{1}$ University of Alabama \\ ${ }^{2}$ University of Alabama at Birmingham \\ ${ }^{3}$ University of Mississippi Medical Center \\ ${ }^{4}$ Alabama Quality Assurance Foundation
}

\begin{abstract}
Applying to graduate school involves strategic planning and preparation. There is an array of considerations and factors that can influence the decision to pursue masters- level education and beyond. A brief synopsis of the graduate school application process is provided so that individuals pursuing a higher level of academia can gain insight on how to optimize their chance of attaining acceptance into programs of choice.
\end{abstract}

(c) 2005 Californian Journal of Health Promotion. All rights reserved.

Keywords: graduate school, professional development, master's degree, student

Assuming that you have an idea of what course of study you want to embark on, applying to graduate school is a sophisticated science in itself. The expansive growth of graduate-level programs in the United States (Rovaris, 2003) can leave interested candidates in the dark about tactical approaches when it comes to putting together a quality application package. The following paper intends to outline critical considerations when committing oneself to a new level of higher education.

Why graduate school? The answer to this basic question essentially sets the framework of your subsequent application elements. Are you contemplating the pursuit of graduate study due to aspirations of advancing your base of knowledge, sharpening a specific skill set, or simply because you have a love of scholarship? Perhaps having the ability to broaden career options or enhancing salary earning potential trigger your decision (Pettit, 2004). Research also identifies that some applicants driven to graduate school are attempting to avoid a stagnant job market or are downright unsatisfied with their current career (Davis, Dandoy, \& Greaves, 2003). Capturing your reasons in writing during an ongoing brainstorm activity addressing the 'why' question will serve as the basis for identifying your graduate journey goals and objectives, as well as creating your personal statement, which are undoubtedly sections of a graduate school application.

As you transition from considering graduate school to actually investigating program possibilities, there are an array of factors that may assist you in deciding which universities you will apply to. The cost, duration, and location of the program commonly influence decisions. Relying on bank support for tuition or facing an 18-month to two or more year reduction of your current work schedule certainly may impact your choice. Knowing whether or not you would move cross-country based on acceptance into a highly respected program might affect potential graduate school opportunities. National ranking systems and reports, such as Carnegie classifications or U.S. News and World Graduate School Reports can also help you gain insight into a school's quality and reputation. Checking into the program format, requirements and curriculum can assist in deciding what program suits you best. In today's world, some students or professionals cannot opt for full-time study and may be 
looking specifically for distance education alternatives. Knowing that a university may have a standardized test requirement, such as the Graduate Record Examination (GRE), or a minimum undergraduate grade point average threshold is a major consideration when selecting which programs you may pursue. Also, if you are interested in gaining particular skills but you do not see that the course offerings or departmental faculty are involved in your areas of interest, you may be less likely to spend time on completing an application. Lastly, for individuals whose aspirations are to obtain a $\mathrm{PhD}$, knowing if a master's thesis, outside of comprehensive exams, is a requirement or an option for certain programs may weigh into your graduate school decisions as well (Rovaris, 2004).

Table 1 may help you visually compare and contrast universities when you reach the point of needing to prioritize study venues that are aligned with what is most important to you. Try to tailor the table to include factors that are critical influences on which programs are worth completing the application process. A completed table can also serve another evaluative purpose. Upon notification of acceptance, you may find the table useful to review when you make your final decision of where to attend.

Table 1

Sample Graduate School Application Prioritization Tool

\begin{tabular}{|l|l|l|l|}
\hline Factor & University 1 & University 2 & University 3 \\
\hline Cost & & & \\
\hline Rank & & & \\
\hline Location & & & \\
\hline Format & & & \\
\hline Duration & & & \\
\hline Requirements & & & \\
\hline Faculty & & & \\
\hline Curriculum & & & \\
\hline Application Costs & & & \\
\hline Funding/Support & & & \\
\hline Other & & & \\
\hline Total & & & \\
\hline
\end{tabular}

Note. Higher scores indicate preferential options.

Scoring: $0=$ Sub-standard; $1=$ Tolerable; $3=$ Ideal

In order to narrow your choices of application submission, try to identify the top three universities that have the greatest overall appeal.

\section{Sources of Graduate School Information}

Aside from online and library investigation, additional collection of data and observation regarding graduate school programs is encouraged. Touring a campus, reviewing media overviews, and talking with current students and alumni are great ways to gain diverse perspectives on possible graduate programs. If attending a school function or departmental activity is an option, try to capitalize on getting an insider's sense of the program's personality and culture. Ask yourself if you think you would be comfortable with the people you meet, especially the faculty, and whether the environment suits you.

After making a substantial effort to explore your graduate program options, you are at the point of starting the application process. The first step is to obtain application materials either by request 
or download. Most packets will provide a checklist that clearly identifies what constitutes a complete application. If standardized test scores, such as the GRE, are required, make sure that you plan well in advance to prepare for and take these tests. Remember there can be delays from the time you take an exam until the time official score reports can be sent to respective institutions. You will want to make sure you are able to receive the scores with ample time to meet deadlines. You may also want to allow for exam retakes if you are not satisfied with original test results. Likewise, you will want to order official transcripts from all undergraduate institutions you attended well in advance.

Another chief element in the application may be obtaining letters from references. You will want to take time to identify professionals who will be able to write a positive recommendation on your behalf. Choose individuals who you know will be responsive to your request in a timely manner. Reflect on your undergraduate academic experience, employment history and service, as well as volunteer or community involvement to brainstorm possible individuals who know you in some light. Oftentimes individuals in positions of high rank, such as an associate or full professor, or who have notable achievements are favored. Furthermore, make sure you meet with your potential references to find out what they will say about you. You surely do not want your future jeopardized by a reference that does not effectively communicate any of your strengths.
Before approaching potential candidates to recommend you to a program, ask yourself if this person can attest to your scholarly ability and potential, your integrity and motivation to succeed, and your character and work ethic. Although your references may have a fair understanding of your academic and personal sincerity, it would be wise to share your CV and goal/personal statements with those you approach for recommendations. You do not want to assume that your references have ample understanding of what your long-term goals are.

Once your application is complete and submitted, you can relax. Sometimes waiting for a response is the worst part of the process. Although not all graduate programs require an interview as an additional step to determine acceptance, following up with a self-initiated campus visit cannot hurt your admission chances and may be a testament to your determination to get in. Whether on an interview or visit, try to mention names of people whose work you are familiar with or perhaps who you know. Remember to be confident and patient and soon enough you will discover what program is the right match for you. And if you will not be among the upcoming cohort, do not be discouraged. Contact the department to find out what application elements can be strengthened for future application attempts. It will make you a better candidate the next time around.

\section{References}

Davis M. V., Dandoy, S., \& Greaves, W. W. (2003). Graduate programs: What is their contribution to the training of the public health workforce? American Journal of Preventive Medicine, 24, 371-2.

Pettit, M. L. (2004). Graduate school in health education: A challenge to consider. Californian Journal of Health Promotion, 2(1), 29-31.

Rovaris, D. J. (2003). Graduate school: still a good idea. The Black Collegian Online. Retrieved February 10, 2005, from http://www.black-collegian.com/graduateschool/goodidea2003-1st.shtml

Rovaris, D. J. (2004). How to successfully manage the grad school process. The Black Collegian Online. Retrieved February 10, 2005, from http://www.black-collegian.com/graduateschool/manage2004$\underline{1 \text { st.shtml }}$ 
Author Information

Sheryl M. Strasser, PhD

University of Alabama

College of Human Environmental Sciences

Department of Health Sciences

Lucy Annang, $\mathrm{PhD}$

University of Alabama at Birmingham

School of Public Health

Department of Health Behavior

Jessica L. Muilenburg, PhD, MPH

University of Mississippi Medical Center

Division of Epidemiology

Department of Preventive Medicine

Marc O. Etienne, DDS, MPH

Alabama Quality Assurance Foundation

Hospital Quality Team

Birmingham, Alabama 